\title{
Extracellular Matrix Proteins in the Anterior Pituitary Gland
}

\author{
John. J. Evans, ${ }^{* 1,2,3}$ and Kenny Chitcholtan ${ }^{1}$
}

\author{
${ }^{1}$ Department of Obstetrics and Gynaecology, ${ }^{2}$ Centre for Neuroendocrinology and ${ }^{3}$ MacDiarmid Institute for Advanced \\ Materials and Nanotechnology, University of Otago, Christchurch, 2 Riccarton Avenue, Christchurch 8011, New \\ Zealand
}

\begin{abstract}
The importance of the extracellular matrix (ECM) has become recognised as an important component of the functioning of cells. However the roles of the ECM in the anterior pituitary gland have received little attention. The pituitary has the particular characteristics of possessing a number of endocrine cells as well as less well studied nonendocrine cells. Because each cell has specific and vital roles in the physiology being of an individual the ECM must also possess selective activities. The details of ECM behaviour have not yet been delineated in the pituitary and this review first considers general characteristics of ECM compounds and then examines the properties of peptides with regard to functioning of the cells of the pituitary. It is noted that there are variations between ECM associated with normal cells and with tumours, that there are both morphological and biochemical responses to alterations in the composition of substrate on which cells are grown, and that a development of further models of ECM will be required for continued advances in the understanding of the manner in which the pituitary behaves in normal, clinical and pathological circumstances. Overall, the observations suggest that modulation of the ECM provides opportunities for enhancing well-being of individuals.
\end{abstract}

Keywords: Extracellular matrix, pituitary, lactotroph, somatotroph, gonadotroph, corticotroph, thyrotroph, galectin, brevican, Chagas disease.

\section{INTRODUCTION}

The anterior pituitary is a complex conglomerate of tissue. A number of relationships exist between its components in its mature form. The interactions and the distinct functioning of the various cell types are at least partly controlled by the extracellular matrix (ECM) Fig. (1), and the boundary itself of the pituitary possesses ECM [1]. Both secretory cells and stromal cells may contribute to pituitary ECM production. These cells can respond to stimuli such as growth factors and cytokines and hence ECM components may be produced within the adenohypophysis as well as being transported to the cells from other tissues. The ECM is well established as being an important component of function of the diverse range of tissues that make up an organism, providing information resulting partly from the spatio-mechanical environment specific to the tissue, which is translated via cell-surface molecules and cytoskeleton properties to appropriate gene activation and protein expression.

The development of cells beginning at the embryonic stage and continuing until reaching adulthood is highly regulated by environmental cues. Crucial information can be provided via ECM components that surround the multiple cell types. Epithelial cells, endothelial and stromal cells interact with the ECM in cell development and function. The ECM proteins partly function as a scaffold to maintain tissue and organ structure. Additionally, the ECM can influence

\footnotetext{
*Address correspondence to this author at the Department of Obstetrics and Gynaecology, University of Otago, Christchurch, PO Box 4345, Christchurch 8140, New Zealand; Tel: 64 - 3 - 3641698;

E-mail: john.evans@otago.ac.nz
}

several aspects of cell behaviour; these include the regulation of cell proliferation, growth, survival, change in cell shape, migration, and differentiation. Integration of the array of signals mediated by both cell-cell and cell-matrix interaction is required to regulate several aspects of cell behaviour, including cell polarity, adhesion, and survival. Importantly, such regulated interactions are also required for homeostasis; aberrant interactions between cells and their microenvironment may simultaneously change the activity of multiple cell pathways and thence alter cell function. Thereby it has been proposed that mechanical distortion induces local changes in cell growth, contributing to carcinogenic processes [2].

This review will first briefly describe the structure and functions of the ECM-associated proteins, collagen IV, laminin, fibronectin, integrin and cadherin, that have been observed to be prominent in anterior pituitary gland phenotypes. Second, the review will cover aspects of the ECM in development and function of the pituitary gland.

\section{COLLAGEN-IV}

Unlike most collagens, collagen-IV occurs only in the basement membrane and comprises up to six genetically distinct $\alpha$-chains designated $\alpha 1(\mathrm{IV})$ to $\alpha 6(\mathrm{IV})$. Each chain contains three structurally distinct domains; an aminoterminal domain rich in cysteine and lysine residues, a major collagenous region with Glycine-X-Y triple repeats of approximately 1,400 residues, followed by an about 230residues long carboxy-terminal noncollagenous domain [3]. The NC1 domain can be considered as the initial director for the molecular assembly of the collagen-IV molecules $[4,5]$. However, the chains interact and assemble with a remarkable 


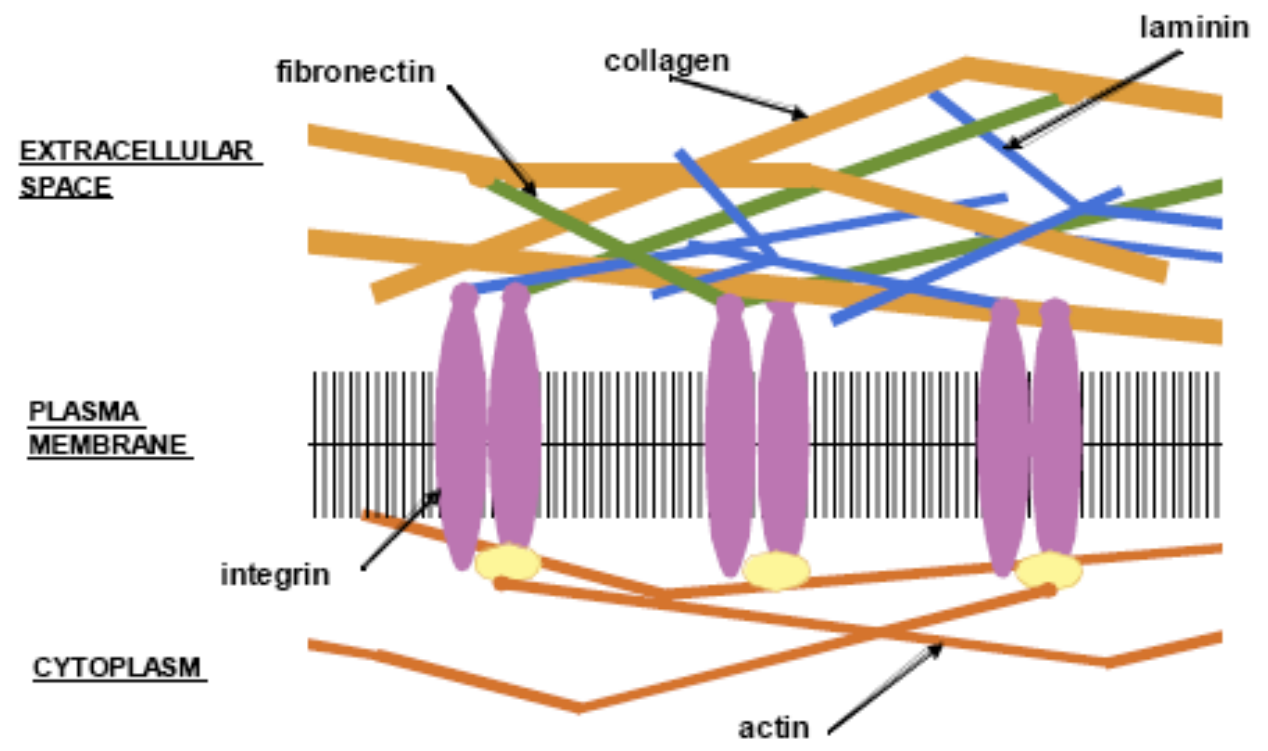

Fig. (1). A diagramatic representation of components of the extracellular matrix.

specificity to form only three distinct heterotrimers of $\alpha 1 \alpha 1 \alpha 2, \alpha 3 \alpha 4 \alpha 5$ and $\alpha 5 \alpha 5 \alpha 6$. The $\alpha 1(\text { IV) })_{2} \alpha 2$ (IV), which was the first described and thus is called the "classical" protomer, is found in the basement membrane of all tissues, whereas the other four chains have tissue-specific distribution. Type IV collagen is involved in the formation of sheet or protein membranes that surround tissues such as basement membranes. These basement membranes are formed by a fine network of cords that are laced together and entrap large associated molecules such as the lamininnidogen complex and the heparan sulphate proteoglycan [6].

\section{COLLAGEN-I}

Type I collagen is an ECM protein present is many tissues, including skin, tendon, bone, and blood vessels, but apparently less so in pituitary. The basic structure of collagen-I contains three polypeptide $\alpha$ chains, which contain the sequence repeat Glycine-X-Y motifs [7]. A proline amino acid is frequently observed at the $\mathrm{X}$ position and hydroxyproline being common at the Y. Collagen-I is classified among the fibril-forming collagens, which also include collagens II, III, V, XI, XXIV, XXVII which are composed of a large continuous triple helix [8, 9]. Collagen members of a given subclass share a common chain structure. Once the major triple helix has formed, the amino acid and carboxyl ends undergo processing [10]. Collagen-I is synthesised in the form of a precursor, which is secreted by exocytosis into the extracellular space where the $\mathrm{N}$ - and C-terminals of procollagen are cleaved by peptidase [11]. Procollagen is formed by cleavage of the signal peptide of preprocollagen $[12,13]$.

\section{LAMININ}

Laminins are extracellular heterotrimeric glycoproteins composed of combinations of $\alpha, \beta$, and $\gamma$ chains. Domains of laminin $\alpha, \beta$, and $\gamma$ chains are comprised of rodlike EGF-like tandems, globular domains and long arms of alpha helical coils [14]. However, only $\alpha$ chains have a distinct globular domain, consisting of five repeats, at the C-terminal; these repeats are absent in $\beta$, and $\gamma$ chains. There are five $\alpha$, four $\beta$, and three $\gamma$ chains [15] and they generate 15 known laminins (laminins 1-15). The $\beta$ and $\gamma$ chains interact with other compounds of the ECM. For instance, the $\gamma 3$ chain of laminin 15 and $\gamma 1$ chain of laminin 1 bind to nidogen, while the $\beta 3$ chain of laminin 5 binds to collagen-VII [15]. Laminin subunits are co-translationally glycosylated with high mannose oligosaccharide side chain, a process that takes place in the rough endoplasmic reticulum. Glycosylation of laminin subunits protects these products from degradation. The trimerisation of laminins is initiated by the stable association of the $\beta$ and $\gamma$ chain and the $\alpha$ chain then combines with this dimeric complex and the trimeric molecule is able to be secreted [15].

\section{INTEGRIN}

A variety of cell surface receptors have been recognised for their ECM binding activity and the best-characterised cell surface adhesion molecules are integrins. Integrins are heterodimers of non-covalently associated $\alpha$ and $\beta$ subunits that consist of an extracellular domain, which is responsible for ligand binding, and a cytoplasmic domain, which plays a vital role in conveying signals from outside to inside cells. Each individual subunit has a large amino terminal consisting of more than 700 residues forming the extracellular domain, and a cytoplasmic domain that in most cases consists of 20-70 residues. One exception is the cytoplasmic domain of the $\beta 4$ subunit that contains 1000 amino acid residues [16]. In vertebrates, there are 8 known $\beta$ subunits and 18 known $\alpha$ subunits that are combined to form 24 distinct integrins [17]. The integrins can be grouped into subgroups based on ligand-binding properties (Table 1).

One third of integrins bind to ligands that contain the amino acid sequence, RGD, including fibronectin, vitronectin, and fibrinogen [18]. RGD peptides can be employed to evaluate the involvement of RGD-binding integrins in certain events, but lack of an effect of RGD peptides does not exclude integrin involvement in a process since most integrins bind ligands that do not possess RGD 
Table 1. Individual Integrins Selectively or Specifically Recognise Various ECM Compounds

\begin{tabular}{|c|c|c|}
\hline $\begin{array}{c}\text { Collagen Receptors } \\
\text { (GFOGER) }\end{array}$ & $\begin{array}{c}\text { Fibronectin Receptors } \\
\text { (RGD) }\end{array}$ & Laminin Receptors \\
\hline \hline$\alpha 1 \beta 1, \alpha 2 \beta 1, \alpha 10 \beta 1, \alpha 11 \beta 1$ & $\alpha 5 \beta 1, \alpha 8 \beta 1, \alpha \mathrm{V} \beta 8, \alpha \mathrm{V} \beta 6, \alpha \mathrm{V} \beta 5, \alpha \mathrm{V} \beta 3, \alpha \mathrm{IIb} \beta 3$ & $\alpha 3 \beta 1, \alpha 6 \beta 1, \alpha 7 \beta 1, \alpha 6 \beta 4$ \\
\hline
\end{tabular}

[17]. Basement membrane proteins, such as laminin, contain an RGD sequence but the sequence is not bound by the laminin-binding integrins. Collagen-binding integrins recognise the triple-helical amino acid GFOGER sequence [19].

The $\alpha$ and $\beta$ subunits show no homology to each other, but different $\alpha$ subunits have similarities among themselves. The $\beta$ subunits share homology in the cytoplasmic tail, with tyrosine residues able to bind intracellular proteins containing a phosphotyrosine binding domain. The binding of integrins to ECM leads to a conformation change and a signal is activated at the contact site via cytoskeleton proteins such as actin and intermediate filament proteins [20]. The cytoplasmic domain of integrins binds directly or indirectly to several proteins, including talin, vinculin, filamin, paxillin, and tensin [21, 22].

Tyrosine kinases, including focal adhesion kinase (FAK) and Src kinases, bind to integrins as they become phosphorylated. A well documented example of signalling via integrin engagement is the activation of Ras-MAPK pathway by adaptor protein Shc, which becomes phosphorylated and binds to the Grb2-Sos complex, which leads to the activation of Ras-MAPK signalling [16]. Activation of the PI3K response occurs, with the subsequent activation of the Akt [23].

\section{FIBRONECTIN}

Fibronectin is a modular protein, which consists of an array of type I, II and III repeat domains. The functional fibronectin molecule consists of two similar or identical subunits of $220-250 \mathrm{kDa}$ that are held together by two disulfide bonds near their carboxyl-termini and is secreted as the dimer, the dimerisation being required for the formation of fibrillar fibronectin matrix [24]. In human, fibronectin can exist as two forms; cellular fibronectin (cFN), which is found in tissues where it is assembled into a fibrillar matrix, and plasma fibronectin ( $\mathrm{pFN})$, which is produced by hepatocytes and is released into the blood where it remains as soluble form circulating at 230-650 ug/ml [25]. Fibronectin fibrils are prominent in loose connective tissue, granulation tissue, embryonic basement membranes and on the surface of numerous cell types in culture. Fibroblast cells can produce fibronectin matrix and that will support the tissue production of fibronectin locally [26].

A large number of integrins can bind to fibronectin. For example the well-studied fibronectin receptor, $\alpha 5 \beta 1$ integrin, recognises the RGD cell binding site in the III domain, along with a synergy sequence (PHSRN) located in the adjacent III domain [27]. The $\alpha 5 \beta 1$ integrin is expressed by vascular endothelial cells [28]. In addition to its cell-binding properties, fibronectin also binds other glycoproteins, including other ECM molecules such as collagens, heparan sulphate proteoglycans, as well as components of the complement and coagulation systems [27]. Fibronectin binds strongly to fibrin and fibrinogen shortly after tissue injury and, along with activated platelets, makes up the bulk of the provisional haemostatic clot [24].

\section{E-CADHERIN}

Cadherin is a superfamily of calcium-mediated membrane glycoproteins, forming one of the four classes of adhesion molecules. Epithelial (E)-cadherin, neuron $(\mathrm{N})$ cadherin and pan $(\mathrm{P})$-cadherin are found in epithelial cells. The establishment of epithelial cell polarity is regulated by junctional proteins in a network [29]. Adherent junctions are formed by the action of E-cadherin of one cell which binds to E-cadherin of an adjacent cell [30]. The cytoplasmic domain of E-cadherin directly interacts with catenin proteins, which appear as $\alpha-, \beta-$, and $\gamma$-catenins [31]. Moreover, catenin proteins connect to the actin cytoskeleton. Thus, it has been suggested that cell-cell communication via homotypic E-cadherin interactions initiates cell signalling [32]. In carcinogenesis, the tumour cells must dissociate from one another before dissemination. Therefore, these adhesion molecules are thought to play an important role in the processes of carcinogenesis and metastasis. Poorly differentiated cancer and invasive cancer cells have low or no expression of E-cadherin [33]. The low expression of Ecadherin may be due to the methylation of E-cadherin promoters [34]. Furthermore, some growth factors such as hepatocyte growth factor, which activate c-Met tyrosine kinase receptor, can alter the expression of E-cadherin, subsequently cancer cells become motile $[31,35]$. Hence, Ecadherin is also known as a tumour suppressor protein [36].

\section{ECM AND THE ANTERIOR PITUITARY GLAND}

Modulation of production of the components of the ECM, including receptor molecules, will subsequently influence endocrine cell behaviour and hormone secretion [37]. Hence paracrine loops within the pituitary gland, which may involve stromal cells, can participate in controlling synthesis and secretion of active hormones which then act at distant sites of the body [38]. The possible central role of the ECM in paracrine interactions that regulate the anterior pituitary cell function and the response of cells to hypothalamic releasing factors was noted some time ago [39]. In one study of the pituitary a stromal lineage, the APS9 cells, was developed. These cells are myofibroblasts that produce a complex basement membrane and form specific intercellular contacts and exhibited a specific functional interaction with GH3B6 prolactinoma cells. They influenced the organisation of the endocrine cells and their secretory activity. Basement membranes of endothelial and perivascular connective tissue cells express many ECMassociated components, such as different isoforms of laminin and fibronectin, collagen-IV, entactin, and heparan sulphate proteoglycans, associated with the corresponding integrin subunits on cell membranes [40-45]. 
The presence of the traditional molecules that are involved in ECM activities were reported in the pituitary almost three decades ago. In normal adenohypophysis parenchyma laminin is abundantly expressed [46]. Laminin was observed to be expressed in basement membranes and in endocrine cells and nonendocrine folliculo-stellate cells of the rat pituitary $[38,40,47]$ in vivo and in primary cultures. The presence of laminin in the adenohypophysis of lactating female rats was also demonstrated [48]. Studies of mice detailed the distribution of laminin around vessels, in the parenchyma and cytoplasm of most of the cells [46]. Similar distribution was observed in normal human pituitaries. In the pituitary gland of the adult rat laminin immunoreactivity has been found intracellularly within membranous cisternae of endocrine cells of the anterior lobe [40, 47]. Labelled secretory granules were observed in gonadotrophs, thyrotrophs, corticotrophs, and lactotrophs; however, not usually in somatotrophs: each glandular cell type seemed to display a specific pattern of the subcellular distribution of laminin immunoreactivity. It was suggested that the intracellular distribution of laminin reflected either a vesicular pathway for laminin export or an exocytotic route by which membrane-bound laminin can be exposed on the cell surface [40].

The expression of $\alpha 1 \beta 1, \alpha 3 \beta 1$ and $\alpha 5 \beta 1$ integrins in adenohypophysial cells of male rats was reported [49]. Other receptors, namely $\alpha 6 \beta 1$ complex (laminin receptor), $\alpha 5 \beta 1$ (fibronectin receptor) and the CD44 molecule (hyaluronic acid receptor) were detected, by cytofluorometric analysis, in the majority of the cells of GH3B6 PRL cells [38]. The presence of receptors as well as the ligand compound provides strong biochemical evidence of the potential for paracrine actions by the pituitary cells.

Components related to the ECM, fibronectin, laminin, or collagen-IV, have been detected in the pituitary from the early stages of embryonic development of the pituitary of Golden Syrian hamsters in Rathke's pouch, prior to cell differentiation to glandular type [50], thus suggesting that ECM may be involved in developmental changes. Proteoglycans may be involved in generating the intercellular conditions appropriate for optimal molecular interactions.

Epidermal growth factor acting through receptors on the cytoskelton alters the morphological characteristics of anterior pituitary cells of infantile (14-day-old) female Wistar rats in a manner dependent on the interaction with the ECM and adhesion processes, an effect that is absent in adults [51]. Thus the cytoskeleton itself develops in the manner in which it is involved in cell modulation during the lifespan of the animal. In fact the cells of the anterior pituitary attach to specific cell types by means of adhesion factors, and so express characteristics of the gland via its topographic details [52].

\section{CANCER AND THE ECM}

Some of the effects related to the ECM found in other cancers have also been noted in the pituitary. It has been suggested that pituitary tumours in vivo are not surrounded by basement membrane [53]. Hence some of the regulating effects due to peptides localised in the basement membrane may be absent from that source and reduced overall.
Therefore the activities of ECM and integrins are important not only to physiological functions, but also to tumorigenesis.

ECM can influence migration, growth, morphology, differentiation and other cellular functions, and the observations suggest that tumoral cell lines do not completely lose their capacity of producing the basal membrane components. During cell immortalization, the process of proliferation and survival becomes independent from integrin-mediated cell adhesion to the ECM, this being one of the critical steps of tumour development [54, 55]. During the process of pituitary adenoma development fibronectin isoforms are differentially expressed [44] such that production of fibronectin isoforms containing the extradomains $\mathrm{A}$ and $\mathrm{B}$ and a differentially O-glycosylated oncofetal form occurs. Alpha-integrins seem not to be involved in pituitary tumorigenesis, except for $\alpha 3$ that probably transduces signals through $\beta 1$-activation, which is a compound that correlates with pituitary adenoma cell transformation [56]. In human adenomatous stroma there are more integrin subunits expressed than in normal tissue - $\alpha 1$, $\alpha 3, \alpha 5, \alpha v, \beta 1$ and $\beta 3$ and others in adenomatous endothelial cells $-\alpha 6, \beta 4$ and $\beta 5$ [56]. More recently it has been revealed that integrin- $\beta 1$ expression is related to invasiveness of adenomas [57]. The functioning of the cells will be thereby altered by the modified presence of ECM-related compounds, for example in regard to adhesiveness and subsequent dissemination.

Additionally, in different types of pituitary tumours, laminin is differentially expressed and localized from that which occurs in the normal pituitary, suggesting a regulatory role for laminin in pituitary tumour development [43]. Integrity of the ECM appears to also influence the expression of the protooncogene c-fos in pituitary adenomas [58] and specific enzymes from the family of matrix metalloproteinases possess activity in pituitary tumour cells to modify the ECM and thence regulate tumour cell proliferation and hormone secretion [59]. There is therefore substantial support for the concept that components of the extracellular matrix are implicated in pituitary tumorigenesis [60].

\section{ENDOCRINE CELLS}

Each of the endocrine cell types in the pituitary that are associated with the different hormonal types has been noted to interact with the ECM. The effects have been suggested to be observed in relation to localisation of the hormones, their levels of expression and the secretory activity, and attachment, proliferation and morphology of the cells. These characteristics are discussed below in simple cell type categories. The limited amount of investigation so far on ECM in the adenohypophysis precludes more detailed subdivision at this stage. The physical substratum on which cells grow is revealed to be an important factor determining cell behaviour.

\section{Lactotrophs}

Laminin has been detected intracellularly in lactotrophs [40, 47, 48]. In the normal pituitary, cells expressing PRL are sited close to laminin-containing cells [46]. Additionally laminin was demonstrated to be in the Golgi and in some 
mature granules in PRL-expressing cells in anterior pituitaries of lactating female rats [48]. Distinct differences in distribution under a variety of physiological circumstances, including suckling and weaning, suggested that laminin and PRL are controlled by independent pathways [48]. Receptors are present, providing support for the concept that pituitary cell-to-ECM interactions occur through transmembrane receptors, such as those of the integrin family [38].

Prolactinoma is the most common pituitary tumour in adults accounting for $60 \%$ of all functioning pituitary adenomas [61]. In contrast to the situation in normal tissue, in human prolactinomas laminin expression was substantially restricted to the basal membrane around blood vessels. In prolactinomas most PRL-expressing cells were found at a distance from, rather than near to, those expressing laminin, therefore having less contact with laminin [46]. The observation that laminin expression in human pituitaries is reduced as prolactinomas progress suggests that in fact laminin activity may be a factor in modifying tumour development [46].

Laminin was detected in GH3B6 cells, which is a subclone of a cell line isolated from a mammosomatotropic tumour of the rat pituitary. GH3B6 cells synthesize and secrete PRL and laminin was observed to be homogenously distributed in most cells and at the periphery of dividing cells and a few others [38]. No significant difference was found in integrin $\beta 1$ expression between normal pituitary tissue and prolactinomas from the D2R _/_ mice. Therefore, integrin $\beta 1$ expression seems not to be involved in prolactinoma development in these mice. Of other compounds, fibronectin was observed mainly around nuclei and sometimes peripherally, and collagen-IV was strongly stained with a similar distribution to laminin in GH3B6 cells [38]. When GH3B6 cells were cultured on substrates of laminin, fibronectin or collagen-IV there was no observable difference in the pattern of PRL staining [38].

Three decades ago it was observed that PRL-secreting adenoma cells adhered more strongly to ECM produced by bovine corneal endothelial cells than to plastic [62]. Similarly there was increased adherence when GH3B6 cells were cultured on laminin, fibronectin or collagen-IV substrates [38]. Also Matrigel (a commercial product, of BD Biosciences, derived from Engelbreth-Holm-Swarm (EHS) mouse sarcoma cells, being an ECM-like mix of proteins) increased the rate of attachment with GH3 cells. The observed effects of Matrigel on GH3 cells may be interpreted in light of the observation that there is an absence of surrounding basement membrane in pituitary tumours in vivo $[53,63]$. Adherence of GH3B6 cells was also enhanced by the presence of stromal (ASP9) cells [37] indicating a potential importance of the non-endocrine cells in pituitary behaviour.

Growth rate of cells cultured on laminin was similar to that of cells cultured on plastic whereas cells cultured on Matrigel did not show a significant increase in cell number. Matrigel apparently decreased the proliferation rate to half of that on plastic, although on Matrigel the increase in apoptosis may mask increases in proliferation [63]. ECM which was produced by bovine corneal endothelial cells maintained a high rate of cell proliferation of $\mathrm{GH} 3$ cells, which causes the confluent condition in long-term culture [64]. It has also been shown that laminin produces a significant decrease of cell proliferation in GH3 cells [46] and notably is reduced in prolactinomas.

Matrigel had dramatic effects on adenohypophyseal cell morphology [65] whereby cells were maintained as a rounded shape longer than cells on glass or laminin. Further, in primary culture of pituitary cells it was demonstrated that collagen induced cells to develop processes similar to neurons [66]. A similar formation of neurite-like processes occurred in GH3B6 cells cultivated on individual components, laminin, fibronectin or collagen-IV substrate $[38,67]$. It was observed that ECM extract from bovine corneal endothelial cells induced a more flattened morphology for adenoma cells than growth on plastic [62]. It may be noted that cellular organisation and morphology may also be affected by further influence of stromal elements [37].

It has been reported that in normal rat pituitary cells laminin did not affect PRL secretion [46]. It was confirmed that secretion of PRL from adenohyophyeal cells in vitro is higher during culture on Matrigel than on glass or laminin [65], and also PRL secretion was greater from adenohypophyseal cells of adult rats that were cultured in collagen gels $[62,66]$.

Further, using fetal adenohypophyseal cells it was noted that after 2 days PRL secretion was increased in cultures in Matrigel compared to those on glass or laminin. The increase in secretion from these cells may have suggested that maturation was occurring under the influence of the substratum, this environment being conducive to the differentiation or maturation of lactotrophs in vitro [65]. Similarly, there was an increase in PRL secretion from GH3 cells grown on ECM obtained from bovine corneal endothelial cells, which was accompanied by a concomitant increase of the basal PRL secretion and the accumulation of PRL mRNA [64]. Interestingly cells cultured on plastic were found to respond more strongly than those on ECM to TRH in PRL release [64].

Laminin has been observed to modify the release of PRL from cells of the normal rat pituitary [68], the effect on PRL release depended on the concentration such that low concentrations of laminin were stimulatory and higher concentrations were inhibitory. On the other hand GH3 cells grown on laminin showed a significant inhibition of PRL production [46]. However in another study using GH3 cells laminin increased the secretion of PRL up to 1.5 times and the authors concluded that laminin potentiates PRL secretion by $\mathrm{GH} 3$ rat pituitary cells [67].

In primary culture of pituitary cells it was demonstrated that collagen increases PRL synthesis [66]. Laminin, inhibits the production of PRL and is reduced in prolactinoma tissues. Although after incubation the total number of $\mathrm{GH} 3$ cells cultured on plastic becomes much greater than those cultured on Matrigel, the number of PRL-immunoreactive cells is almost the same in the two groups because a higher proportion of cells in the Matrigel culture express PRL. In this context it has been revealed that from the initial formation of hyperplasia, a dramatic early reduction occurs in laminin expression with the advancement of prolactinoma 
progression [46]. PRL intracellular expression has been observed to be modified also in GH3B6 cells by surface interactions with stromal APS9 cells [37].

The potential importance of cadherin in pituitary pathophysiology has been noted [69]. In other cancer sites it is thought that E-cadherin may act to retain potentially invasive tumour cells at the primary lesion $[70,71]$. The Ecadherin acts through its cytoplasmic linkage via catenins to the actin cytoskeleton [72,73]. These reports may assist in interpreting the observation that expression of E-cadherin and $\beta$-catenin seem to be significantly lower in invasive prolactinomas compared with non-invasive ones [74].

Recently, it was demonstrated that GH3B6 PRL cells can synthesise laminin, fibronectin, collagen-IV, heparan and chondroitin sulphates (and that distribution of the ECM components were not affected by TRH) [75]. The expression of laminin in human prolactinomas is confined to basal membranes surrounding blood vessels despite the fact that it is abundantly expressed in the normal adenohypophysis parenchyma $[46,60]$.

The general trend noted above for laminin to suppress lactotroph activity and the observation that prolactinomas contain less laminin than normal pituitary tissue could suggest that the reduction in laminin has created an environment that is favourable for PRL secreting cells to proliferate faster and increase hormone secretion. These differences between normal and tumour cells in PRL regulation by laminin could be influenced by differences in integrin expression during pituitary tumour development [56, 76].

\section{Somatotrophs}

Effects of the ECM on the level of GH secretion from GH3 cells have been demonstrated. The cells also have altered morphology and adherence in the presence of ECM components, and additionally these GH-secreting cells have faster initial proliferation. That ECM can differentially affect cells has been observed where ECM caused a decrease in GH but an increase in PRL, in association with an increase in rates of proliferation and changes in morphology [77]. On the other hand, laminin did not produce any change in GH secretion in normal pituitary nor in GH3 cells [46]. GH secretion from somatotroph cells in hypothyroid rat pituitary was enhanced by ECM components of corneal endothelial cells [78].

\section{Gonadotrophs}

The ECM has been noted to be important in activation and transmission of signals in gonadotrophs [79]. In particular, actions of GnRH via GnRH-receptor that result in integrin regulation have been detected, whereby $\mathrm{GnRH}$ activated pathways have been demonstrated to induce temporal changes in the composition of the signalling complex that seems to reside in microtubules, and directs the signalling complex along the cytoskeleton to the network of focal adhesions [80] to mediate cell adhesion. The focal adhesions, which alter cytoskeleton and LH- $\beta$ transcription [81], can be disrupted by cytoskeletal inhibitors. Some details have been delineated, and the involvement of Pyk2 tyrosine phosphorylation with ERK activation and c-Src are implicated in the network of cytoskeleton-mediated processes [82]; these steps themselves being regulated by binding of GnRH to the GnRH-R (see [79]). Hence structural integrity of the cell cytoskeleton is central to cell function including GnRH-mediated cell migration and spreading. Thus alteration of character and details of the cytoskeleton $[82,83]$ will modify the temporal and spatial properties of signal activation $[84,85]$.

Fetal adenohypophyseal cells cultured on three substrata, glass, laminin or Matrigel, secreted more LH and FSH on Matrigel than they secreted when cultured on glass or laminin. Thus, Matrigel influences the function and possibly the maturation of fetal adenohypophyseal cells in vitro [65]. Laminin, did not alter FSH secretion, although a stimulatory effect limited to low levels on LH secretion by pituitaries of male rats in vitro was observed. Laminin inhibited the response of FSH to GnRH [68].

Laminin has been detected intracellularly in gonadotrophs of rats [40, 47, 48], and also in the adult mouse in which laminin immunoreactivity has been detected in gonadotrophs (but not other cell types). Laminin is also a constituent of the basal laminae in the adenohypophysis of the mouse pituitary gland [86]. Moreover, within these cells, laminin immunoreactivity was found only in secretory granules and not in Golgi cisternae nor in the endoplasmic reticulum or nuclear envelope. Laminin was not found in the extracellular connective tissue [86].

Thus the results demonstrated that ECM compounds influence the morphology of and hormone (PRL, LH and FSH) secretion from differentiated (adult) and differentiating (fetal) adenohypophyseal cells likely due to cell-matrix interactions that developed over several days.

\section{Corticotrophs}

AtT20 cells, a corticotroph tumour cell line, possess glycosphingolipids as cell surface determinants which enable interactions with neighbouring surfaces [87]. Many of the ECM proteins affect AtT- 20 cells, but do not necessarily have an effect on normal pituitary cells [88], indicating that the ECM may have specific regulatory effects, depending on the specific state of a cell.

Whereas laminin and collagen-I inhibited cell proliferation, fibronectin and collagen-IV significantly stimulate AtT-20 cell proliferation. This suggests a potential role for these ECM components in the progression of corticotroph adenomas. $\beta 1$-integrin was found to stimulate AtT-20 cell proliferation, possibly mediating the activity of fibronectin. Laminin has an antiproliferative effect in corticotroph tumour cells, which appears to be mediated by integrin $\beta 1$ and GTPases [88]. On a fibronectin substrate AtT-20 cells were found to spread and disperse, whereas on laminin, collagen-I and collagen-IV the cells were round and grew in clusters. In AtT-20 cells, laminin, collagen-I and collagen-IV inhibit ACTH biosynthesis at the level of POMC gene transcription [88]. The signal transduction pathways may include the Rho small GTPase.

In cells that were grown as 3-D cell clusters in Matrigel ACTH production was probably similar to that from flattened forms on plastic suggesting that factors, other than morphologies and cell architecture, related to cell state may interact [89]. On the other hand there was no difference in 
mRNA synthesis in normal cells between cells on plastic and on Matrigel [89].

\section{Thyrotrophs}

Hypothyroid rat pituitary cells grown on ECM components of corneal endothelial cells were characteristically epithelial, whereas those cultured on plastic plates had a fibroblast-like appearance. The ECM induced faster proliferation and stronger attachment. Secretion of basal TSH from the cells occurred at a higher level and the response to TRH was enabled in the presence of ECM [78].

\section{FURTHER ASPECTS}

Less intensively studied compounds have also been detected. One is brevican, a member of the aggrecan/versican family of the chondroitin sulfate proteoglycans (CSPGs). For brevican, alternative transcript processing leads to two isoforms [90]. One is secreted, the other is linked to the cell membrane via a glycosylphosphatidylinositol (GPI) anchor. The isoform of brevican that is secreted into the extracellular space appears to be associated with ECM activity. On the other hand GPIanchored brevican may act as a cellular matrix receptor. Secreted-brevican mRNA was expressed in the adult rat pituitary and brevican was found to be present in human pituitary adenoma [91].

It has been noted that another metabolic factor altered in the tumour state is galectin-3 [92]. Galectins are animal lectins that exhibit selective affinity for $\beta$-galactosides [93] and bind to a variety of $\beta$-galactoside-containing glycoproteins and glycolipids both on the cell surface and in ECMs [94]. By binding to these glycoconjugates, galectins deliver signals intracellularly as well as mediate cell-cell and cell-ECM adhesion [95]. Galectins thus affect the process of tumour cell metastasis by modulating cell adhesion and migration [96]. Galactin-3 expression was detected in lactotrophs, corticotrophs and folliculostellate cells of normal human pituitaries; and also in corticotroph and lactotroph adenomas and carcinomas. Inhibition of galectin3 gene activity reduced proliferation, providing evidence that it may have an important role in pituitary cell proliferation and tumour progression [97-99].

The involvement of ECM has been noted to be involved in the pituitary gland in a number of aspects of health. For example in the immune response associated with Chagas disease [100]. It was observed that there was an increase of ECM components (such as fibronectin and laminin) in pituitary glands of infected mice compared to normal animals. Infection of ACTH-producing cells in vitro also resulted in an enhancement of ECM production, suggesting a direct response of the ECM regulating processes to presence of the parasite.

\section{SUMMARY}

The ECM has been well-recognised as a fundamental component of cellular function in the pituitary, although the manner of its actions is not clear. ECM compounds have been detected in cells of the anterior pituitary gland thereby indicating that paracrine effects will follow their secretion. In this review several of the key compounds have been noted. Researchers have concluded that these affect pituitary cells in a way parallel to that of other cells. There appears however to be specific differences for the pituitary, such as the apparent prominence of collagen-IV among the collagens. Both normal function and pathological conditions alter levels of the compounds and differential expression occurs in the specific cell types, thereby providing indirect evidence that ECM is part of the functional processes of a pituitary cell. A substantial foundation has been accumulated with respect to information of behaviour of cell lines and there is steady progress towards obtaining more information on ordinary cells, including details such as the differences between males and females. As the ECM becomes characterised better, the pathways involved will be similarly better understood, with corresponding improvement in opportunities to develop novel treatments of pituitarycentred disorders.

\section{REFERENCES}

[1] Knappe UJ, Fink T, Fisseler-Eckhoff A, Schoenmayr R. Expression of extracellular matrix-proteins in perisellar connective tissue and dura mater. Acta Neurochir (Wien) 2010; 152: 345-53.

[2] Ingber DE. Can cancer be reversed by engineering the tumor microenvironment? Semin Cancer Biol 2008; 18: 356-64.

[3] Hudson BG, Tryggvason K, Sundaramoorthy M, Neilson EG. Alport's syndrome, Goodpasture's syndrome, and type IV collagen. N Engl J Med 2003; 348: 2543-56.

[4] Khoshnoodi J, Cartailler JP, Alvares K, Veis A, Hudson BG. Molecular recognition in the assembly of collagens: Terminal noncollagenous domains are key recognition modules in the formation of triple helical protomers. J Biol Chem 2006; 281: 38117-21.

[5] Borza CM, Borza D, Pedchenko V, et al. Human Podocytes Adhere to the KRGDS Motif of the a3a4a5 Collagen IV Network. J Am Soc Nephrol 2008; 19: 677-84.

[6] Mark K, Park J, Bauer S, Schmuki P. Nanoscale engineering of biomimetic surfaces: cues from the extracellular matrix. Cell Tissue Res 2010; 339: 131-53.

[7] Persikov AV, Ramshaw JAM, Brodsky B. Prediction of Collagen Stability from Amino Acid Sequence. J Biol Chem 2005; 280: 19343-19349.

[8] Ricard-Blum S, Ruggiero F. The collagen superfamily: from the extracellular matrix to the cell membrane. Pathol Biol 2005; 53: $430-42$.

[9] Gordon MK, Hahn RA. Collagens. Cell Tissue Res 2010; 339: 24757.

[10] Brodsky B, Persik AV. Molecular structure of the collagen triple helix. Adv Protein Chem 2005; 70: 301-339.

[11] Jinnin M. Mechanisms of skin fibrosis in systemic sclerosis. J Dermatol 2010; 37: 11-25.

[12] Van Der Rest M, Garrone R. Collagen family of proteins. FASEB J 1991; 5: 2814-23.

[13] Kadler KE, Holmes DF, Trotter JA, Chapman JA. Collagen fibril form. Biochem J 1996; 316: 1-11.

[14] Marinkovich MP. Laminin 332 in squamous-cell carcinoma. Nat Rev 2007; 7: 370-80.

[15] Tzua J, Marinkovich MP. Bridging structure with function: Structural, regulatory, and developmental role of laminins. Int J Biochem Cell Biol 2008; 40: 199-214.

[16] Gilcrease MZ. Integrin signaling in epithelial cells. Cancer Lett 2007; 247: 1-25.

[17] Barczyk M, Carracedo S, Gullberg D. Integrins. Cell Tissue Res 2010; 339: 269-80.

[18] Shimaoka M, Springer TA. Therapeutic antagonists and conformational regulation of integrin function. Nat Rev 2003; 2: 703-715.

[19] Herr AB, Farndale RW. Structural Insights into the Interactions between Platelet Receptors and Fibrillar Collagen. J Biol Chem 2009; 284: 19781-19785.

[20] Belkin AM, Stepp MA. Integrins as receptors for laminins. Microsc Res Tech 2000; 51: 280-301.

[21] Miyazaki K. Laminin-5 (laminin-332): Unique biological activity and role in tumor growth and invasion. Cancer Sci 2006; 97: 91-98. 
[22] Giannone G, Sheetz MP. Substrate rigidity and force define form through tyrosine phosphatase and kinase pathways. Trends Cell Biol 2006; 16: 213-23.

[23] Bon G, Folgiero V, Carlo S, Sacchi A, Falcioni R. Involvement of a6b4 integrin in the mechanisms that regulate breast cancer progression. Breast Cancer Res 2007; 9: 1-5.

[24] White ES, Baralle FE, Muro AF. New insights into form and function of fibronectin splice variants. J Pathol 2008; 216: 1-14.

[25] Zerlauth G, Wolf, G. Plasma fibronectin as a marker for cancer and other diseases. Am J Med 1984; 77: 685-9.

[26] Maurer LM, Tomasini-Johansson BR, Mosher DF. Emerging roles of fibronectin in thrombosis. Thromb Res 2010; 125: 287-291.

[27] Leiss M, Beckmann K, Giró A, Costell M, Fässler R. The role of integrin binding sites in fibronectin matrix assembly in vivo. Curr Opin Cell Biol 2008; 20: 502-7.

[28] Astrof S, Hynes RO. Fibronectins in vascular morphogenesis. Angiogenesis 2009; 12(2): 165-5.

[29] Mège R, Gavard J, Lambert M. Regulation of cell-cell junctions by the cytoskeleton. Cur Opin Cell Biol 2006; 18: 541-48.

[30] Miyoshia J, Takai Y. Molecular perspective on tight-junction assembly and epithelial polarity. Adv Drug Deliv Rev 2005; 57: 815- 55 .

[31] Lilien J, Balsamo J. The regulation of cadherin-mediated adhesion by tyrosine phosphorylation/dephosphorylation of b-catenin. Curr Opin Cell Biol 2005; 17: 459-65.

[32] Anastasiadis PZ. p120-ctn: A nexus for contextual signaling via Rho GTPases. Biochim Biophys Acta 2007; 1773: 34-46.

[33] Oka H, Shiozaki H, Kobayashi K, et al. Immunohistochemical evaluation of E-cadherin adhesion molecule expression in human gastric cancer. Virchows Arch A Pathol Anat Histopathol 1992; 421: 149 -56.

[34] Leung WK, Man EPS, Yu J, et al. Effects of Helicobacter pylori Eradication on Methylation Status of E-Cadherin Gene in Noncancerous Stomach. Clin Cancer Res 2006; 12: 3216-21.

[35] Zenga G, Aptea U, Micsenyia A, Bella A, Monga SPS. Tyrosine residues 654 and 670 in â-catenin are crucial in regulation of Metâ-catenin interactions. Exp Cell Res 2006; 312: 3620-30.

[36] Margulis A, Zhang W, Alt-Holland A, Crawford HC, Fusenig NE, Garlick JA. E-cadherin suppression accelerates squamous cell carcinoma progression in three-dimensional, human tissue constructs. Cancer Res 2005; 65: 1783-91.

[37] Alves LM, Werneck CC, Martins Rd Rde C, et al. A continuous lineage of rat adenohypophysis stromal cells: characterisation and effects on $\mathrm{GH}(3) \mathrm{B}(6)$ prolactin-secreting cell behaviour. Biol Cell 2002; 94: 519-33.

[38] de Carvalho DF, Silva KL, de Oliveria DA, et al. Characterization and distribution of extracellular matrix components and receptors in GH3B6 prolactin cells. Biol Cell 2000; 92: 351-62.

[39] Perez FM, Rose JC, Schwartz J. Anterior pituitary cells: getting to know their neighbors. Endocrinology 1995; 111: C1-C6.

[40] Vila-Porcile E, Picart R, Tixier-Vidal A, Tougard C. Cellular and subcellular distribution of laminin in adult rat anterior pituitary. J Histochem Cytochem 1987; 35: 287-99.

[41] Vila-Porcile E, Picart R, Vigny M, Tixier-Vidal A, Tougard C. Immunolocalization of laminin, heparan-sulfate proteoglycan, entactin and type IV collagen in the rat anterior pituitary. II. An in vitro study on primary cultures. Anat Rec 1992; 233: 1-12.

[42] Vila-Porcile E, Picart R, Vigny M, Tixier-Vidal A, Tougard C. Immunolocalization of laminin, heparan-sulfate proteoglycan, entactin, and type IV collagen in the rat anterior pituitary. I. An in vivo study. Anat Rec 1992; 232: 482-92.

[43] Farnoud MR, Derome P, Peillon F, Li JY. Immunohistochemical localization of different laminin isoforms in human normal and adenomatous anterior pituitary. Lab Invest 1994; 70: 399-406.

[44] Farnoud MR, Farhadian F, Samuel JL, Derome P, Peillon F, Li JY. Fibronectin isoforms are differentially expressed in normal and adenomatous human anterior pituitaries. Int J Cancer 1995; 61: 2734.

[45] Murray K, de Lera JM, Astudillo A, McNicol AM. Organisation of basement membrane components in the human adult and fetal pituitary gland and in pituitary adenomas. Virchows Arch 1997; 431: 329-35.

[46] Kuchenbauer F, Theodoropoulou M, Hopfner U, et al. Laminin inhibits lactotroph proliferation and is reduced in early prolactinoma development. Mol Cell Endocrinol 2003; 207: 13-20.
[47] Tougard C, Louvard D, Picart R, Tixier-Vidal A. Immunocytochemical localization of laminin in rat anterior pituitary cells in vivo and in vitro. In vitro Cell Dev Biol Anim 1985; 21: 57-61.

[48] Vila-Porcile E, Picart R, Olivier L, Tixier-Vidal A, Tougard C. Subcellular distribution of laminin and prolactin in stimulated and blocked prolactin cells in the pituitary of lactating rats. Cell Tissue Res 1988; 254: 617-27.

[49] Horacek MJ, Kawaguchi T, Terracio L. Adult adenohypophysial cells express beta 1 integrins and prefer laminin during cellsubstratum adhesion. In vitro Cell Dev Biol Anim 1994; 30A: 3540.

[50] Horacek MJ, Thompson JC, Dada MO, Terracio L. The extracellular matrix components laminin, fibronectin, and collagen IV are present among the epithelial cells forming Rathke's pouch. Acta Anat 1993; 147: 69-74.

[51] Toral C, Solano-Agama C, Reyes-Marquez B, et al. Role of extracellular matrix-cell interaction and epidermal growth factor (EGF) on EGF-receptors and actin cytoskeleton arrangement in infantile pituitary cells. Cell Tissue Res 2007; 327: 143-53.

[52] Noda T, Kikuchi M, Kaidzu S, Yashiro T. Rat anterior pituitary cells in vitro can partly reconstruct in vivo topographic affinities. Anat Rec A Discov Mol Cell Evol Biol 2003; 272: 548-55.

[53] Sato K, Hayashi M, Komai T, Kubota T, Kawano H, Handa Y. Clinical and histological study of pituitary fibrosarcoma following radiotherapy for pituitary adenoma. Case report. Neurol Med Chir (Tokyo) 1990; 30: 888-92.

[54] Lukashev ME, Werb Z. ECM signalling: orchestrating cell behaviour and misbehaviour. Trends Cell Biol 1998; 8: 437-41.

[55] Giancotti FG, Ruoslahti E. Integrin signaling. Science 1999; 285: 1028-32.

[56] Farnoud MR, Veirana N, Derome P, Peillon F, Li JY. Adenomatous transformation of the human anterior pituitary is associated with alterations in integrin expression. Int $\mathrm{J}$ Cancer 1996; 67: 45-53.

[57] Wang F, Shu K, Lei T, Xue D. The expression of integrinbeta1 and FAK in pituitary adenomas and their correlation with invasiveness. J Huazhong Uni Sci Technol Med Sci 2008; 28: 572-5.

[58] Pereda MP, Goldberg V, Chervin A, et al. Interleukin-2 (IL-2) and IL-6 regulate c-fos protooncogene expression in human pituitary adenoma explants. Mol Cell Endocrinol 1996; 124: 33-42.

[59] Paez Pereda M, Ledda MF, Goldberg V, et al. High levels of matrix metalloproteinases regulate proliferation and hormone secretion in pituitary cells. J Clin Endocrinol Metab 2000; 85: 2639.

[60] Paez-Pereda M, Kuchenbauer F, Arzt E, Stalla GK. Regulation of pituitary hormones and cell proliferation by components of the extracellular matrix. Braz J Med Biol Res 2005; 38: 1487-94.

[61] Ciccarelli A, Daly AF, Beckers A. The epidemiology of prolactinomas. Pituitary 2005; 8: 3-6.

[62] Bethea CL, Weiner RI. Human prolactin secreting adenoma cells maintained on extracellular matrix. Endocrinology 1981; 108: 35760 .

[63] Lee BL, Yoo MJ, Kim WH, Hwang DH, Lee SK, Kleinman HK. Reconstituted basement membrane reduces proliferation and increases prolactin expression of GH3 cells. Endocr J 1999; 46: 597-604.

[64] Elias KA, Weiner RI, Mellon SH. Effect of extracellular matrix on prolactin secretion and mRNA accumulation in GH3 cells. DNA Cell Biol 1990; 9: 369-75.

[65] Horacek MJ, Dada MO, Terracio L. Reconstituted basement membrane influences prolactin, $\mathrm{LH}$, and FSH secretion from adult and fetal adenohypophyseal cells in vitro. J Cell Physiol 1992; 151: $180-9$.

[66] Martinez-Campos A, Dannies PS. A possible differentiation of anterior pituitary cells in collagen gels into neurons. Cell Tissue Res 1986; 244: 21-6.

[67] Brunet-de Carvalho N, Picart R, Van de Moortele S, Tougard C, Tixier-Vidal A. Laminin induces formation of neurite-like processes and potentiates prolactin secretion by $\mathrm{GH} 3$ rat pituitary cells. Differentiation 1989; 40: 106-18.

[68] Denduchis B, Rettori V, McCann SM. Role of laminin on prolactin and gonadotrophin release from anterior pituitaries of male rats. Life Sci 1994; 55: 1757-65.

[69] Gurlek A, Karavitaki N, Ansorge O, Wass JA. What are the markers of aggressiveness in prolactinomas? Changes in cell 
biology, extracellular matrix components, angiogenesis and genetics. Eur J Endocr 2007; 156: 143-53.

[70] Vleminckx K, Vakaet L, Jr., Mareel M, Fiers W, van Roy F. Genetic manipulation of E-cadherin expression by epithelial tumor cells reveals an invasion suppressor role. Cell 1991; 66: 107-19.

[71] Shibamoto S, Hayakawa M, Takeuchi K, et al. Association of p120, a tyrosine kinase substrate, with E-cadherin/catenin complexes. J Cell Biol 1995; 128: 949-57.

[72] Ozawa M, Baribault H, Kemler R. The cytoplasmic domain of the cell adhesion molecule uvomorulin associates with three independent proteins structurally related in different species. EMBO J 1989; 8: 1711-7.

[73] Gumbiner BM, McCrea PD. Catenins as mediators of the cytoplasmic functions of cadherins. J Cell Sci 1993; 17 (uppl): 5158.

[74] Qian ZR, Li CC, Yamasaki H, et al. Role of E-cadherin, alpha-, beta-, and gamma-catenins, and p120 (cell adhesion molecules) in prolactinoma behavior. Mod Pathol 2002; 15: 1357-65.

[75] Carvalho MA, Arcanjo K, Silva LC, Borojevic R. The capacity of connective tissue stromas to sustain myelopoiesis depends both upon the growth factors and the local intercellular environment. Biol Cell 2000; 92: 605-14.

[76] Farnoud MR, Lissak B, Kujas M, Peillon F, Racadot J, Li JY. Specific alterations of the basement membrane and stroma antigens in human pituitary tumours in comparison with the normal anterior pituitary. An immunocytochemical study. Virchows Arch A Pathol Anat Histopathol 1992; 421: 449-55.

[77] Prysor-Jones RA, Silverlight JJ, Jenkins JS. Differential effects of extracellular matrix on secretion of prolactin and growth hormone by rat pituitary tumour cells in vitro. Acta Endocrinol 1985; 108: 156-60.

[78] Spira O, Vlodavsky I, Ulmansky R, et al. Thyrotrophin and growth hormone secretion and cell morphology in hypothyroid pituitary cells cultured on a natural extracellular matrix. Acta Endocrinol 1983; 104: 279-86.

[79] Maudsley S, Naor Z, Bonfil D, et al. Proline-rich tyrosine kinase 2 mediates gonadotropin-releasing hormone signaling to a specific extracellularly regulated kinase-sensitive transcriptional locus in the luteinizing hormone beta-subunit gene. Mol Endocrinol 2007; 21: 1216-33.

[80] Dobkin-Bekman M, Naidich M, Rahamim L, et al. A preformed signaling complex mediates GnRH-activated ERK phosphorylation of paxillin and FAK at focal adhesions in L beta $\mathrm{T} 2$ gonadotrope cells. Mol Endocr 2009; 23: 1850-64.

[81] Gardner S, Pawson AJ. Emerging targets of the GnRH receptor: novel interactions with Wnt signalling mediators. Neuroendocri 2009; 89: 241-51.

[82] Davidson L, Pawson AJ, Millar RP, Maudsley S. Cytoskeletal reorganization dependence of signaling by the gonadotropinreleasing hormone receptor. J Biol Chem 2004; 279: 1980-93.

[83] Navratil AM, Knoll JG, Whitesell JD, Tobet SA, Clay CM. Neuroendocrine plasticity in the anterior pituitary: gonadotropin- releasing hormone-mediated movement in vitro and in vivo. Endocrinology 2007; 148: 1736-44.

[84] Caunt CJ, Finch AR, Sedgley KR, McArdle CA. GnRH receptor signalling to ERK: kinetics and compartmentalization. Trends Endocrinol Metab 2006; 17: 308-13.

[85] Wang Q, Lu R, Zhao J, Limbird LE. Arrestin serves as a molecular switch, linking endogenous alpha2-adrenergic receptor to SRCdependent, but not SRC-independent, ERK activation. J Biol Chem 2006; 281: 25948-55.

[86] Nunez EA, Pomeranz HD, Gershon MD, Payette RF. Distribution of laminin in the murine pituitary. Anat Rec 1990; 226: 471-80.

[87] Whitmore CD, Hindsgaul O, Palcic MM, Schnaar RL, Dovichi NJ. Metabolic cytometry. Glycosphingolipid metabolism in single cells. Anal Chem 2007; 79: 5139-42.

[88] Kuchenbauer F, Hopfner U, Stalla J, Arzt E, Stalla GK, PaezPereda M. Extracellular matrix components regulate ACTH production and proliferation in corticotroph tumor cells. Mol Cell Endocrinol 2001; 175: 141-8.

[89] Kim HJ, Hwang IT, Lee HK, et al. Reconstituted basement membrane induces glandular-like morphogenesis but no difference in ACTH synthesis of anterior pituitary cells. Endocr J 2000; 47: 771-6.

[90] Seidenbecher CI, Richter K, Rauch U, Fassler R, Garner CC, Gundelfinger ED. Brevican, a chondroitin sulfate proteoglycan of rat brain, occurs as secreted and cell surface glycosylphosphatidylinositol-anchored isoforms. J Biol Chem 1995; 270: 27206-12.

[91] Dong Y, Han X, Xue Y, et al. Secreted brevican mRNA is expressed in the adult rat pituitary. Biochim Biophys Acta 2004; 314: 745-8.

[92] Nobumoto A, Nagahara K, Oomizu S, et al. Galectin-9 suppresses tumor metastasis by blocking adhesion to endothelium and extracellular matrices. Glycobiology 2008; 18: 735-44.

[93] Kilpatrick DC. Animal lectins: a historical introduction and overview. Biochim Biophys Acta 2002; 1572: 187-97.

[94] Hsu DK, Liu FT. Regulation of cellular homeostasis by galectins. Glycoconjug J 2004; 19: 507-15.

[95] Hughes RC. Galectins as modulators of cell adhesion. Biochimie 2001; 83: 667-76.

[96] Danguy A, Camby I, Kiss R. Galectins and cancer. Biochim Biophys Acta 2002; 1572: 285-93.

[97] Jin L, Riss D, Ruebel K, et al. Galectin-3 Expression in Functioning and Silent ACTH-Producing Adenomas. Endocr Pathol 2005; 16: 107-14.

[98] Riss D, Jin L, Qian X, et al. Differential expression of galectin-3 in pituitary tumors. Cancer Res 2003; 63: 2251-5.

[99] Thodou E, Argyrakos T, Kontogeorgos G. Galectin-3 as a marker distinguishing functioning from silent corticotroph adenomas. Hormones (Athens) 2007; 6: 227-32.

[100] Correa-de-Santana E, Pinto-Mariz F, Savino W. Immunoneuroendocrine interactions in Chagas disease. Ann N Y Acad Sci 2006; 1088: 274-83. 